Meta

Journal des traducteurs

Translators' Journal

\title{
Le complément des compliments
}

\section{Paul A. Horguelin}

Volume 21, numéro 2, juin 1976

URI : https://id.erudit.org/iderudit/003103ar

DOI : https://doi.org/10.7202/003103ar

Aller au sommaire du numéro

Éditeur(s)

Les Presses de l'Université de Montréal

ISSN

0026-0452 (imprimé)

1492-1421 (numérique)

Découvrir la revue

Citer cet article

Horguelin, P. A. (1976). Le complément des compliments. Meta, 21(2), 162-162. https://doi.org/10.7202/003103ar d'utilisation que vous pouvez consulter en ligne.

https://apropos.erudit.org/fr/usagers/politique-dutilisation/ 


\section{LE COMPLÉMENT DES COMPLIMENTS}

La «saison des compliments » est maintenant passée, mais la question soulevée par M. Harris mérite une précision qui complétera la preuve par l'évidence du C.N.R.S.

Clas et Horguelin ne sont pas entièrement muets sur l'objet du litige : la liste des « anglicismes à proscrire » fait mention du calque « Compliments de la saison » (p. 208), également signalé p. 316 , et sous « courtoisie » donne les équivalents «Hommage de, offert par, gracieuseté de» (p. 209). L'index de la nouvelle édition permettra de retrouver plus facilement ces termes.

C'est toutefois dans les fiches du Comité de linguistique de Radio-Canada que l'on trouve la vraie réponse qui met fin aux scrupules, tout en les justifiant. En effet, dans une première fiche non numérotée, le Comité est catégorique :

La maison qui fait cadeau d'un article à un client et l'auteur qui présente un exemplaire de son ouvrage à un ami, commettent un anglicisme s'ils accompagnent leur cadeau de la mention : Avec les COMPLIMENTS de la maison/ de l'auteur.

(Faute) Avec les COMPLIMENTS de la maison X.

(Correct) Avec les HOMMAGES de la maison X. HOMMAGE de la maison $\mathrm{X}$.

La fiche 178, qui annule et remplace la précédente, vient par contre réhabiliter l'expression condamnée :

Pour présenter un ouvrage ou un cadeau, la formule AVEC LES COMPLIMENTS DE, suivie du nom du donateur, est désormais reçue par le bon usage. Elle a été longtemps tenue pour un anglicisme au Canada, sans doute parce que les dictionnaires n'en font pas mention. Les tours AVEC LES HOMMAGES DE/HOMMAGE DE restent corrects.

Souvent l'usage varie, bien fol qui ne le suit!

Paul A. Horguelin 